\title{
Construction of Online English Offline Teaching Mode in the Era of Internet Plus
}

\author{
Zhang Mei* \\ Zhejiang Tongji Vocational College of Science and Technology, Hangzhou, Zhejiang Province, China \\ *Corresponding Author.
}

\begin{abstract}
:
With the rapid development of Internet technology, its application in the field of education is more extensive and diversified, and plays a greater role in teaching. Grammar teaching is an important part of English teaching. The complexity of grammar in forestry English leads to the common problems of English grammar among students. Relying on the Internet technology to establish the cloud classroom intelligent platform, online and offline interactive English teaching can fully play the role of online teaching resources and information technology by combining online and offline. This method can activate the classroom and improve students' language application ability and learning interest. Based on this, this paper analyzes the application of cloud classroom intelligent platform in English teaching. Then this paper discusses its construction method and application strategy, aiming to provide reference for relevant researchers.
\end{abstract}

Keywords: Internet plus, online and offline, interactive forestry English teaching, intelligent platform.

\section{INTRODUCTION}

Based on big data analysis and cloud dynamic application, information-based and intelligent classroom teaching is steadily entering the teaching front line [1-2]. College English teaching reform has officially entered the target implementation stage of resource sharing, instant messaging and personalized learning. Online teaching under cloud classroom intelligent platform arises at the historic moment [3]. Through the intervention of cloud intelligent mobile technology, a convenient and efficient technology connection, knowledge connection and emotional connection can be established between the classroom and the audience, which can effectively realize the interaction between teachers and students, students and students, as well as the interaction between students and the platform and teaching resources [4]. Only by developing college English learning in the direction of personalization, self guidance and 
Article History: Received: 28 October 2021 Revised: 05 December 2021 Accepted: 10 January 2022 Publication: 28 February 2022

intelligence, can we better stimulate interest and desire in learning and improve teaching efficiency.

Cloud classroom intelligent platform is a kind of Internet service platform for education and training industry. By renting the network interactive live technology service, the platform can realize the national high-quality network synchronous and asynchronous teaching and training. Cloud classroom is an all-round interactive mobile teaching platform. From the technical level, cloud classroom is an intelligent classroom. Based on the theory of knowledge construction, dynamic learning data and cloud intelligent application, it constructs an information-based, interactive online and offline interactive classroom teaching model. According to the curriculum standards and teaching objectives, taking the image as the main carrier, focusing on the key and difficult points of knowledge, the relevant teaching contents and teaching methods are gathered, and a series of teaching activities with vertical knowledge mining and horizontal knowledge connection are carried out. The amount of knowledge information transferred is far more than that of traditional classroom, and with its unique color, data (materials), sound, language and so on Image, light, shadow and other elements redefine the connotation of modern intelligent classroom [5-6]. The biggest feature of cloud Classroom Mobile teaching is that teaching breaks through the constraints of region, time and space. As long as there are Internet media tools, learning and communication can be carried out at any time [7].

Cloud classroom brings different teaching experience for teachers and students. For teachers, the cloud classroom platform provides basic teaching services for teachers, such as micro lesson recording, flipped classroom teaching, interactive Q\&A, auxiliary teaching, assignment and other forms, to build a stable and self circulating network teaching space, so that teaching materials, learning data and online and offline learning can be shared dynamically and interactively [8-10]. For students, cloud classroom uses mobile terminal technology, mainly in the form of video watching, micro class learning, question and answer discussion, and runs through the context of knowledge points to provide students with an autonomous learning environment and experience learning results. The mobile teaching space under the cloud classroom intelligent platform provides more accurate personalized services and self-directed learning for teachers and students.

\section{THE SYSTEM STRUCTURE AND FEASIBILITY ANALYSIS OF ONLINE AND OFFLINE INTERACTIVE TEACHING MODE}

\subsection{System structure of teaching mode}

The online and offline interactive teaching mode of cloud classroom intelligent platform is a 
Article History: Received: 28 October 2021 Revised: 05 December 2021 Accepted: 10 January 2022 Publication: 28 February 2022

teaching method combining online digital online education and offline classroom teaching. Its purpose is to promote classroom teaching with the help of online teaching resources and information technology, so as to achieve good teaching effect. Online and offline teaching mode moves part of the teaching content to extracurricular, through the upload of text, video, audio and other resources, students can read and watch online, understand the learning content, get familiar with the key points of knowledge, and then complete the expansion, digestion and absorption of knowledge through offline classroom time.

The online and offline interactive teaching mode subverts the traditional teaching method based on the classroom. It changes the traditional teaching mode, the order of teaching time, the role of teachers and students, and further clarifies the dominant position of students in teaching activities. With the help of modern educational technology and the Internet, the online and offline interactive teaching mode changes the traditional learning environment and teaching links, and reconstructs the learning process, that is, information is transmitted before class, questions are solved in class, and internalization is applied after class. The single classroom listening is transformed into three steps: watching before class, discussing in class, and evaluating after class, New forms of education such as "micro classroom" and "fragment video" appear in the big education environment, which makes a thorough flipped innovation of the traditional classroom. Teachers' online platform provides teaching videos, PPT of knowledge points, key words and other learning materials. Students can independently complete the learning of online resources after class, submit online questions that they can't understand, or ask questions in class. Offline teachers explain the key and difficult points of students' feedback, answer questions, and expand and supplement them appropriately within the framework of basic knowledge, so as to promote students to master knowledge better. Online and offline interactive mode emphasizes student-centered, promotes the development of students' autonomous learning ability, collaborative channel ability and innovation ability, gives full play to students' learning enthusiasm, initiative and creativity, and maximizes the improvement of College English teaching efficiency and quality.

\subsection{Analysis of the feasibility of teaching mode}

(1) The development of online and offline teaching mode benefits from the construction of digital campus. With the deepening of modern teaching reform in Colleges and universities, as well as the national and local investment and support in the field of education, the teaching conditions of colleges and universities have been greatly improved. With the emergence of Internet digital campus, the transformation of multimedia teaching environment has been completed, the hardware infrastructure has been in place, and the classroom has realized "three links", namely broadband network, resource sharing and interactive learning space, which fully 
Article History: Received: 28 October 2021 Revised: 05 December 2021 Accepted: 10 January 2022 Publication: 28 February 2022

meets the requirements of College English teaching cloud classroom intelligent teaching.

(2) The development of online and offline teaching mode benefits from the nourishment and edification of modern media information to students. Online learning has developed into a mixed teaching mode with the integration of traditional teaching. The use of online learning breaks the restrictions of region and time, which is especially suitable for the contemporary post-90s college students. At present, the post-90s college students have been exposed to a variety of modern media since childhood, and are familiar with the convenience and quickness that modern information brings to life and study. Learning based on Internet cloud classroom requires students to watch micro Lesson Videos anytime and anywhere and acquire knowledge through "normalized" Internet and mobile phones. This kind of learning mode will be accepted, cooperated and interesting by students.

(3) The development of online and offline teaching mode benefits from teachers' continuous learning and mastery of modern teaching means. The intervention of Internet media helps teachers grow and innovate in teaching practice. The majority of teachers, especially young and middle-aged backbone teachers, are familiar with the importance and convenience of modern educational technology. They are energetic and have a strong sense of accepting new things and new media. They can consciously adapt to the needs of the Internet era for the development and improvement of teachers' professional ability. They can actively try new technologies and apply multimedia intelligent teaching methods to the classroom to enrich the teaching space, Enrich the teaching content, in order to change and promote their own teaching behavior.

\section{SYSTEM OVERALL DESIGN}

\subsection{System architecture design}

The MVC-based Django framework used in the system, i.e. model -template -view, is shown in fig. 1 as an overview of Django's architecture: 
Article History: Received: 28 October 2021 Revised: 05 December 2021 Accepted: 10 January 2022 Publication: 28

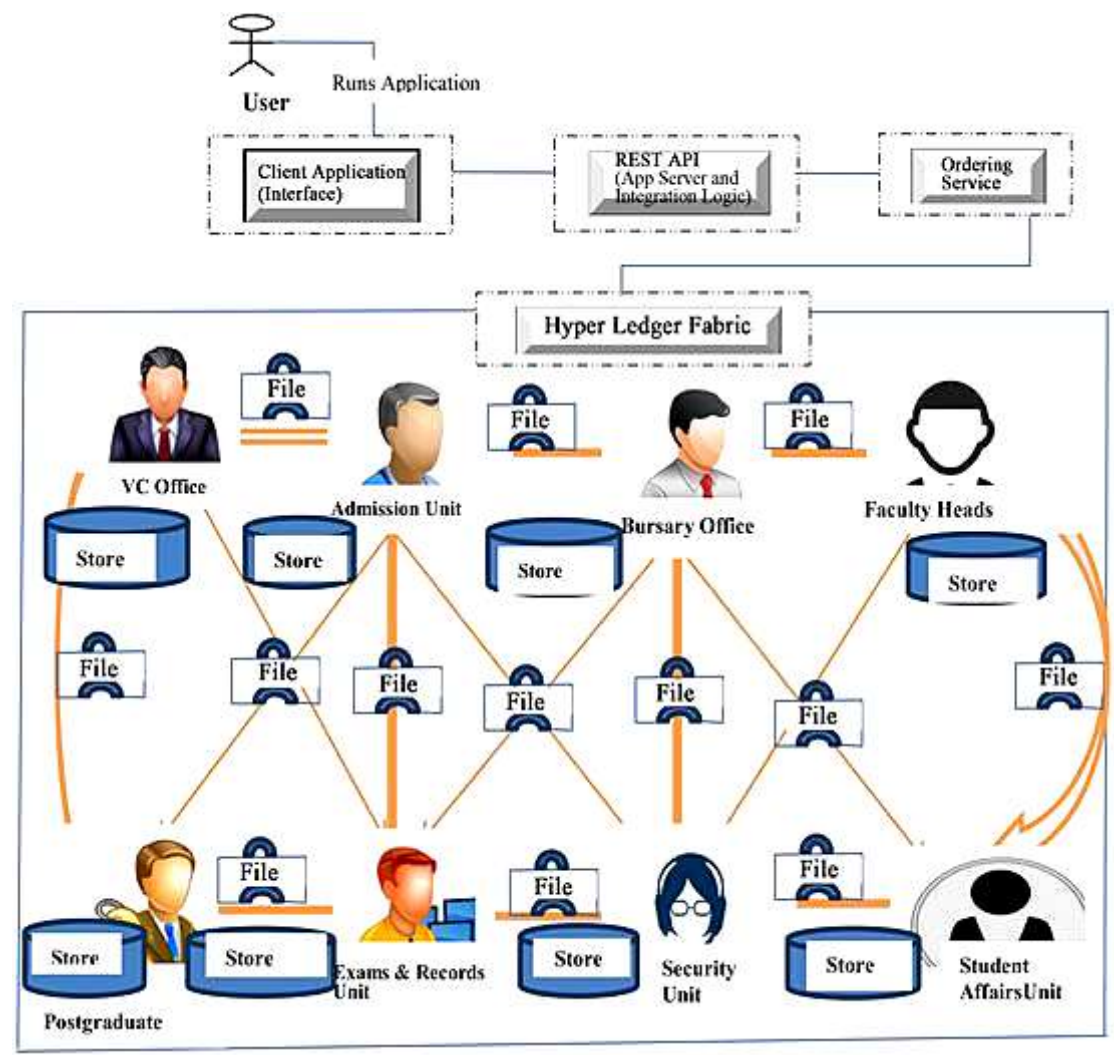

Fig 1: Overview of Django architecture

The architecture design of the system is completely based on the MTV architecture design of Django. Model and database realize ORM (Object-Relation Mapping) relationship. When using it, we do not need to pay attention to the structure level of data in the database, and directly operate the database by operating the Model object. The View in MTV architecture is equivalent to the Controller in MVC, which is used to realize the functions of data transfer and operation transfer between Model and Template. Template is the presentation layer in MTV architecture, which is used to display the data transmitted by View through operating Model for users, and at the same time, transmit the user operation to View to realize the operation of Model. The streaming media server used by the website is Flash streaming media server, and the streaming media service is represented by Flash, so it is directly controlled by Template.

\subsection{Overall function module design}

According to the role, the system is divided into three modules, which are student module, teacher module and background management module. The overall module design of the system is shown in Figure 2. 
Article History: Received: 28 October 2021 Revised: 05 December 2021 Accepted: 10 January 2022 Publication: 28 February 2022

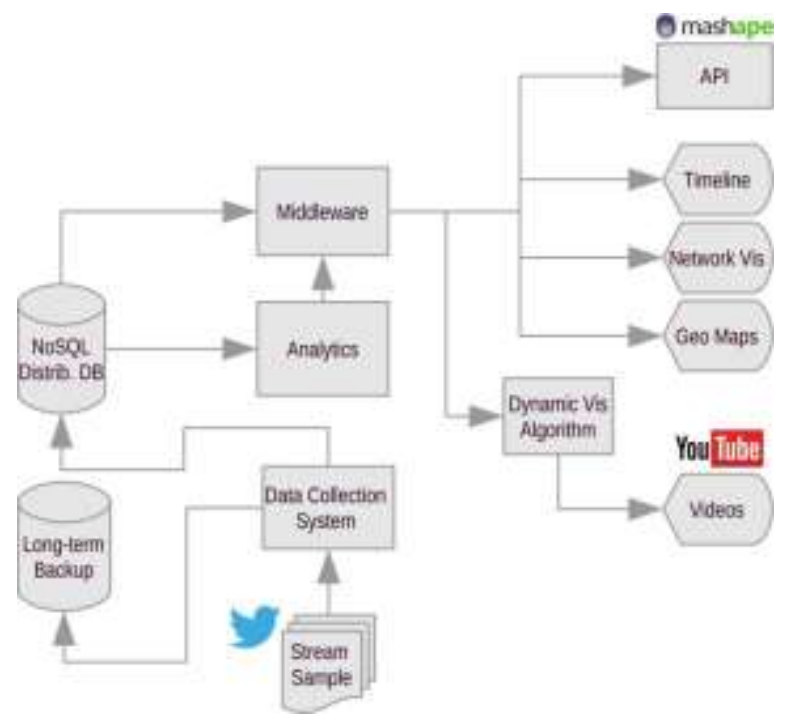

Fig 2: System overall module design diagram

The student module is divided into seven functional modules according to the needs, as shown in Figure 3. Login module functions include registration, login and password retrieval. The online test module completes the English proficiency test function. The function of course management module includes booking courses, viewing courses and cancelling courses. The function of video teaching module includes entering the classroom, ending the course and course evaluation. The function of account management module includes viewing personal information, modifying personal information and password. The function of consumption module includes shopping list, purchasing monthly courses and purchasing study ticket courses. The function of service module includes online customer service and resource download. 
Article History: Received: 28 October 2021 Revised: 05 December 2021 Accepted: 10 January 2022 Publication: 28 February 2022

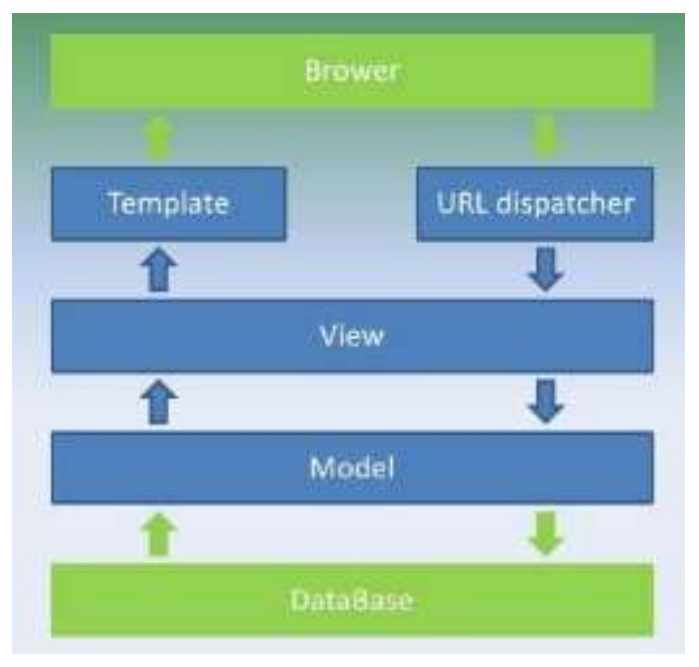

Fig 3: Student module design

The division module is divided into five functional modules according to the requirements, as shown in Figure 4. Login module functions include teacher login and password retrieval. The functions of the teacher teaching module include viewing the courses that have been reserved, viewing the students' information and the teacher's class. The history module completes the function of viewing history. The account management module completes the function of personal information management. The function of service module includes online customer service and resource download.

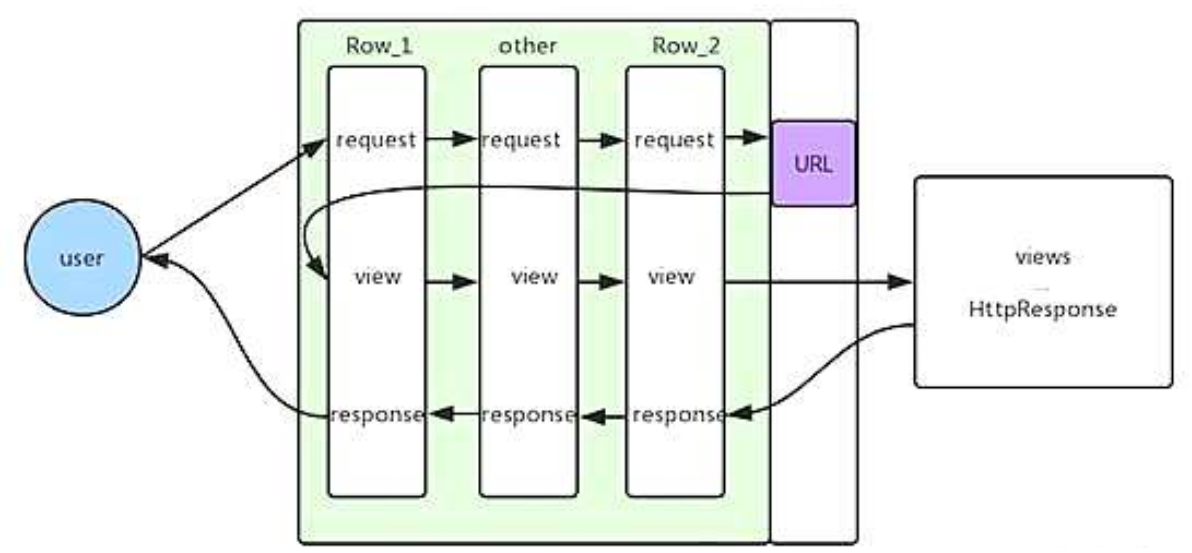

Fig 4: Teacher module design drawing

\subsection{Database design}


Article History: Received: 28 October 2021 Revised: 05 December 2021 Accepted: 10 January 2022 Publication: 28 February 2022

The database used in the system is mongodb non relational database. There are 10 database tables, which are administrator table, advertisement table, activity display table, curriculum table, system log table, monthly card package table, study ticket package table, news table, student table and teacher table. The curriculum is the core operation database table of the system, and the main business and operation of the system are around the curriculum.

The administrator table stores information about all administrators. The administrator logs in with mailbox and password, and the administrator has different roles and different permissions. Its structure is shown in Table 1.

\section{TABLE I. Administrator table}

\begin{tabular}{|c|c|c|c|}
\hline \multicolumn{4}{|c|}{ CLASS NAME: ADMIN } \\
\hline FIELD & $\begin{array}{r}T \\
\text { YPE }\end{array}$ & $\begin{array}{l}\text { LEN } \\
\text { GTH }\end{array}$ & REMARKS \\
\hline email & $\begin{array}{r}\mathrm{e} \\
\text { mail }\end{array}$ & 60 & Administrator mailbox \\
\hline $\mathrm{e}$ Nicknam & ing $^{\text {str }}$ & 20 & Nickname \\
\hline $\begin{array}{l}\text { Real } \\
\text { name }\end{array}$ & ing $^{\text {str }}$ & 20 & Real name \\
\hline $\begin{array}{l}\text { Passwor } \\
\text { d }\end{array}$ & ing $^{\text {str }}$ & 20 & Password \\
\hline Role & ing $^{\text {str }}$ & 20 & Role \\
\hline Active & ing $^{\text {str }}$ & 20 & Activation state \\
\hline
\end{tabular}

The advertisement table stores all the advertisement information displayed on the page. Advertising status is divided into published and unpublished. Its structure is shown in Table 2.

TABLE II. Advertisement list

\begin{tabular}{|c|rr|c|l|}
\hline \multicolumn{4}{|c|}{ CLASS NAME: ADVERTISEMENT } \\
\hline \begin{tabular}{|c|c|c|} 
FIE \\
LD
\end{tabular} & \multicolumn{2}{|c|}{ TYP } & $\begin{array}{c}\text { LEN } \\
\text { GTH }\end{array}$ & REMARKS \\
\hline name & & string & 20 & Advertisement name \\
\hline
\end{tabular}


Article History: Received: 28 October 2021 Revised: 05 December 2021 Accepted: 10 January 2022 Publication: 28 February 2022

\begin{tabular}{|c|c|c|c|}
\hline date & $m e^{\text {dateti }}$ & 20 & Date of issue \\
\hline ibe & string & 200 & Advertisement description \\
\hline $\mathrm{e}^{\text {activ }}$ & string & 20 & Release status \\
\hline
\end{tabular}

\section{IMPLEMENTATION AND APPLICATION OF ONLINE AND OFFLINE INTERACTIVE TEACHING MODE}

The engine of College English teaching reform in the future is "learning as the main body" and "interactive teaching". Cloud classroom supported by Internet technology has built an intelligent platform for College English teaching. Through the online upload of various learning resources such as micro class video, audio, text materials, discussion questions and exercise library, students are encouraged to learn autonomously, have subjective cognition, and develop the ability to discover and solve problems. While ensuring the uploading of learning materials, teachers should also prepare offline classroom teaching, prepare students' questions and queries, and make objective evaluation and Reflection on the teaching effect.

\section{(1) Teacher preparation online resource preparation}

Resources are uploaded to the cloud classroom platform, which is the key link of online intelligent teaching. The preparation of online resources must be completed in three aspects: first, sort out the key points and key points of knowledge, and make teaching materials such as teaching video, audio and PPT. The second is to design relevant thinking questions or discussion questions. After watching the video or reading the online text, the students can discuss and answer immediately. Third, the production of exercise bank, through exercises, test the effect of learning, to maintain a positive attitude towards autonomous cognition. The preparation of online resources is to enable students to have a clear understanding of the teaching content before class, pay more attention to the content that they don't understand, and stimulate their desire for learning.

\section{(2) Online Autonomous Learning for students}

Online Autonomous Learning is a typical feature of intelligent learning in cloud classroom platform. Students can arrange their own extracurricular time for online learning before class. The form and way of learning are flexible. Computers and mobile phones are available, and are not limited by time and place. Online autonomous learning needs to complete three tasks: one is to watch videos, PPT and other materials online, and study the key and difficult information in 
Article History: Received: 28 October 2021 Revised: 05 December 2021 Accepted: 10 January 2022 Publication: 28 February 2022

videos and text materials. The second is to consolidate the learning content and solve the general problems through the exercises in the exercise bank. The third is to discuss or feedback on the platform for the problems that can not be solved, so that teachers can reasonably arrange the offline classroom teaching in the later stage.

\section{(3) Offline interactive classroom teaching}

The purpose of offline classroom teaching and online learning is to refine the key points, analyze the difficulties, solve the questions, broaden the thinking and expand the vision, so as to promote the consolidation and mastery of knowledge and maximize the teaching effect. Offline interactive classroom teaching must meet the following three aspects of teaching requirements: first, to meet the basic knowledge of intensive teaching, according to the feedback of students' online problems, teachers focus on explaining in class, consciously extract key knowledge points, and guide students to think. Second, to meet the needs of the development of open knowledge teaching, the development of College English teaching focuses on the spread of language knowledge and the intake of cultural awareness, constructs a broad and flexible knowledge base, improves the ability of language speculation and humanistic quality, and meets the needs of students' development to professional English. Third, to meet the practical teaching of applied knowledge, according to the basic skills of language listening, speaking, reading and writing, we should strengthen the input and output of language, design a variety of pragmatic scenarios, stimulate knowledge transfer, and cultivate language innovation ability.

\section{(4) Monitoring of students' Online Autonomous Learning}

Teachers must participate in the whole process of autonomous learning with the main characteristics of students' autonomy and self orientation, and follow-up monitoring and learning evaluation. Before the beginning of each topic unit or task module, students are required to read the task notice and requirements in time, and complete the corresponding learning tasks within the specified time. For the study of video, audio and other materials, set up group discussion, hand in notes and other forms to check. During the play of the study materials, you can also intersperse the discussion and answer of questions, or carry out simple tests. You can also choose video chat, conference, discussion and other forms to communicate with students under the menu "interactive classroom". There is also an effective monitoring method to check the attendance rate and online rate of students through the check-in code. The frequency and effect of students' participation in learning can also be reflected through the platform data, so that teachers can understand the overall situation of teaching and objectively evaluate students' online learning. 
Article History: Received: 28 October 2021 Revised: 05 December 2021 Accepted: 10 January 2022 Publication: 28 February 2022

(5) Teachers' Reflection on teaching after class

Barrows HS, an American professor of Neurology, founded problem-based learning (PBL) in 1960s. PBL teaching method is based on cognitive psychology. It takes problem posing as the starting point and active problem solving as the guidance. It puts forward problem-based learning with learners as the main body. It emphasizes setting learning into complex and meaningful problem situations, so as to capture the scientific knowledge hidden behind problems and form problem-solving skills and autonomous learning ability. The online and offline interactive teaching mode under the cloud classroom intelligent platform is a problembased active experiential learning method, which integrates knowledge, practice and methodology, focuses on images and video clips, and inspires students to find, analyze, answer and evaluate problems, and improves communication skills as well as critical and creative thinking, To build a "theme knowledge node group" with clear theme, diverse categories and rigorous layout. The ultimate goal of online and offline interactive teaching mode is to guide students to think, rather than simply impart knowledge. Students' learning has clear pertinence and direction, their learning will present a relaxed and happy state.

\section{CONCLUSION}

The communication effects studied in this paper are divided into cognitive and emotional levels. The cognitive level is from the perspective of knowledge memory, and the research is short-term memory. The duration of short-term memory is generally considered to be about one minute. Therefore, this study conducted a memory test after the respondents read the materials. Therefore, the long-term memory effect of current political data news has not been studied. In addition, this paper takes the chart part of data news as a whole. However, due to the variety of charts, this study has not been able to measure the differences between different kinds of charts, such as column chart, bubble chart, map, radar chart and so on.

\section{REFERENCES}

[1] Huang Jianbin, Shao Yongzhen. the Way out of CET Reform. Foreign Language Circles, 1998 (04): 20-22

[2] Zhou Yuanqing. the Construction of Excellent Course Materials is an Important Measure of Teaching Reform and Innovation. China Higher Education Research, 2003 (1): 12-12

[3] Zhong Qiquan, Jiang Meiling. Value Orientation and Path of Teaching Reform Under the Background of New Curriculum. Education Research, 2004, 025 (008): 32-36

[4] Wang Zongping, Zhuang Huihua. Emphasizing Fitness and Neglecting Competition -- Reform and Practice of College Physical Education. Sports Science, 2001, 021 (001): 22-25 
Article History: Received: 28 October 2021 Revised: 05 December 2021 Accepted: 10 January 2022 Publication: 28 February 2022

[5] Li Zhiyi, Zhu Hong, Liu Zhijun. Guiding the Teaching Reform of Higher Engineering Education with the Concept of Achievement Oriented Education. Higher Engineering Education Research, 2014, 000 (002): 29-34

[6] Ye Lan. Let the Classroom Radiate Vitality -- on the Deepening of Teaching Reform in Primary and Secondary Schools. Education Research, 1997 (09): 3-8

[7] Zhao Yongfeng, Jiao Li, Zheng Hui. Analysis of Xinjiang Oasis Tourism Environment Early Warning System . Resources and Environment of Arid Area, 2008 (07): 144-149

[8] Lou Wengao, Wang Guanglei, Feng Guozhen. Research on Topsis Evaluation of Tourism Safety Early Warning and Its Application . Tourism Journal, 2013, 22:11-18

[9] Teng Weifeng. Analysis on the Hierarchy and Emphasis of China's Overseas Tourism Early Warning . Safety and Environmental Engineering, 2006, 13: 58-64

[10] Xu Mei, Liu Chunla, Li Dan. Dynamic Early Warning of Tourism Ecological Security in Zhangjiajie City Based on Improved Topsis Grey Gm (1,1) Model . Journal of Applied Ecology, 2017 (11): 284292 